\title{
Sanda Renko and Blaženka Knežević (Editors): Trade Perspectives in the Context of Safety, Security, Privacy and Loyalty
}

\author{
Publisher: Cambridge Scholar Publishing, 2018, Cambridge, UK. \\ ISBN 978-1-52750-841-5
}

Scientific books are usually not overall exciting to the average reader who is not highly specialized in the area examined in such a book. However, a monograph entitled Trade Perspectives in the Context of Safety, Security, Privacy and Loyalty brings an exciting and dangerous sounding topics connected with terrorism, theft, piracy and product counterfeiting in a retail trade and accompanying supply chains, among some other topics. Such themes offer reader a pleasure of breaching out of ordinary trade topics into some unchartered territory. At the same time those are the buzzvowrds and topics that "bombard" us on a daily basis from the mainstream media.

Such interesting reading material is a product of series of papers presented at the scientific conference Trade Perspectives 2016 that took place at the Faculty of Economics and Business at University of Zagreb. The chapters in a book represent a selection of updated papers which are authored by academics from 10 academic institutions from 5 different European countries. Book editors are Sanda Renko and Blaženka Knežević who are two prominent professors from the Trade Department at Faculty of Economics and Business at the University of Zagreb. The book has been published in the year 2018 by Cambridge Scholars Publishing from United Kingdom and has been entirely written in the English language. It consists of eleven chapters totaling 294 pages.

Monograph opens with the chapter concerning supply chain resilience in the aftermath of the some worldwide known terrorist attacks ranging from the $9 / 11$ to the most recent events. The importance of resilience of a supply chains was examined as it becomes quite important on a globalized market place where a disturbance on one side of the world might have an adverse effects on a production and retail on many geographically distant markets. Successful supply chains must be able to withstand or to minimize the effects of all possible disruptions, such as terrorist attacks, on all of the partners engaged in the chain. Second chapter examines how terrorism affects trade and tourism. It presents a research which determined that there is a correlation 
between the number of terrorist incidents and tourist arrivals in a selected countries such as Egypt. Research also produced evidence that international trade, especially in services sector also suffers increasingly with the number of the terrorist attacks. Next chapter deals with the assessment of shrinkage in a retail trade in Croatia. Shrinkage as loss of inventory in retail trade is mostly due to the shoplifting, employee theft, administrative loss and suppliers' fraud. After giving an estimation for the Croatia it is clear that this topic should be in depth explored because such losses are taken into account when forming a prices. Higher prices influence what and where consumers purchase. Chapter four explores the security of international trade supply chains in regard to the threat of modern maritime piracy. Most of such piracy acts today appear in the Somali region and Gulf of Aden. Their frequency and intensity is decreasing and it is concluded that their impact on international supply chains is only marginal. It seems that counterfeiting has become much larger problem than piracy nowadays. In chapter five authors point to the adverse effects that counterfeiting has on economy and companies whose intellectual property and trademarks have been abused. Some of the solutions are in strengthening legal framework for punishing such behavior as well as educating consumers about the potential risks to their health and safety when buying a counterfeited goods. In the next chapter contributing authors discuss security and legal protection for consumers and an ethical problems in the international trade. Chapter analyses four basic ethical problems of international trade which are almost completely ignored in the literature such as dumping, economic sanctions, fair trade, listing fees for new products, and so on. The best way to protect companies and markets from such violations is to implement a good national legislation and a membership in an international trade organizations whose goals are to promote free and fair international trade on a global level. The topic of international trade continues in the next chapter investigating trade facilitation agreement tool to facilitate and secure trade. Based on the WTO Trade Facilitation Agreement, OECD developed Trade Facilitation Indicators in order to measure their relative economic and trade impact on trade flows and costs. Authors come up with several conclusions organized into three groups of recommendations for the trade policies: increased application of electronic data and information, increased transparency of trade facilitation regulation supported with the establishment of national trade facilitation committees, and increased external border agency cooperation.

Chapter eight explores the risks associated with the efforts of the creation of loyal consumers in the Croatian FMCG market. In a conducted empirical research authors found out that the Croatian retail market has been dominated by the importance of product assortment and price sensitivity, while promotion and store ambient were less important for the consumers' selection of a retailer. However, most of Croatian consumers are found not to be loyal which implies the importance and values of marketing strategies aimed at increasing consumer loyalty. The following chapter deals with highly important issues of security and privacy in the mobile commerce 
in Croatia and Serbia. Research results showed that shoppers are not satisfied with privacy and security efforts of retailers and policymakers in both countries. Security issues have been more important to the consumers than the privacy issues. Paying more attention to the privacy concerns in mobile commerce should produce significant positive effects on the retailers' business results.

Chapter regarding safety issues of low energy micro-location technology in retailing explores micro-location technology that interacts through a smartphone application that enables location of a customer in a real time and triggers a suitable promotional response. Such technology is beneficial for the retailers because they can covey specific, customized promotional offers to the customers based on their unique profile. Benefits for the consumers include better information about the location and about the products they are seeing. Research results among Croatian consumers show that they believe that such technology will enhance their shopping experience and effectiveness in purchasing. However, retailers and consumers are aware of privacy and safety challenges in adopting it for wider application. Last chapter in this book is dedicated to the safety and loyalty in a footwear retail in Croatia. Research results pointed that loyalty is directly related to satisfaction and factors that most influence consumer loyalty are the quality and durability of footwear, obtained value for the price, location of the store and post-purchase service.

Presented topics and text have been engaging for reading. Because of the interesting issues explored thorough the book it is clear that it offers fresh and valuable body of new knowledge regarding topics of international trade, supply chains and retailing. Facts and research presented in the book are sound and methodologically grounded. Chapters are written in a professional and constructive manner. That is why this book is warmly recommended as a valuable source of information and knowledge for the students, lecturers and professionals in the field of international trade and retailing.

Mirko Palić

Faculty of Economics and Business, University of Zagreb, Zagreb, Croatia 
